\title{
Las políticas culturales en Zacatecas a examen
}

Daniel Hernández Palestino*

\author{
El proyecto de desarrollo turístico enmarcado en el modelo neoliberal pretende atraer \\ inversionistas privados y reinsertar a Zacatecas en la lógica de la globalización. \\ Los gobiernos prïstas de los ochentas y noventas implementan un proyecto orientado \\ a la mercantilización y ampliación de la oferta cultural. Con la alternancia, \\ los posteriores gobiernos perredistas pretenden construir una imagen urbana \\ renovada con una infraestructura cultural, además de que promueven actividades \\ culturales con pretensiones internacionales. Sin embargo, el desencadenamiento \\ de la violencia criminal y la descomposición social durante la presidencia de Felipe \\ Calderón trastocaron el proyecto turístico cultural generando procesos \\ de discontinuidad y ruptura en la política cultural.
}

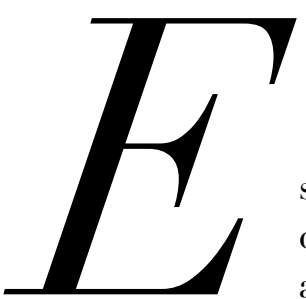

N EL PRESENTE ARTÍCULO se evalúa el resultado de las políticas culturales en el estado de Zacatecas, a partir de la aplicación de las reformas estructurales del neoliberalismo. Se identifican dos fases en momentos clave: la primera, durante el periodo del régimen priista I982-I998, en el cual se finca un proyecto de desarrollo turístico orientado hacia una dinámica mercantilista y la ampliación de una nueva oferta cultural. Los periodos gubernamentales dominados por el Partido de la Revolución De-

* Docente-investigador de la Unidad Académica de Antropología de la Universidad Autónoma de Zacatecas, México. mocrática (PRD), que coinciden con la etapa presidencial panista, se caracterizan por una estrategia de gestión gubernamental para dotar al estado de una nueva imagen urbana, una infraestructura cultural y la promoción de actividades culturales con aspiraciones internacionales.

Con esta plataforma se trató de atraer la atención de los inversionistas privados a Zacatecas en el sector turístico e insertar al estado en la órbita de la globalización. No obstante, el estallido del crimen organizado y el desgarramiento del tejido social durante el régimen de Felipe Calderón impactó severamente los planes de desarrollo turístico cultural para el estado de Zacatecas, lo cual se refleja actualmente con la discontinuidad y ruptura de las políticas culturales. 


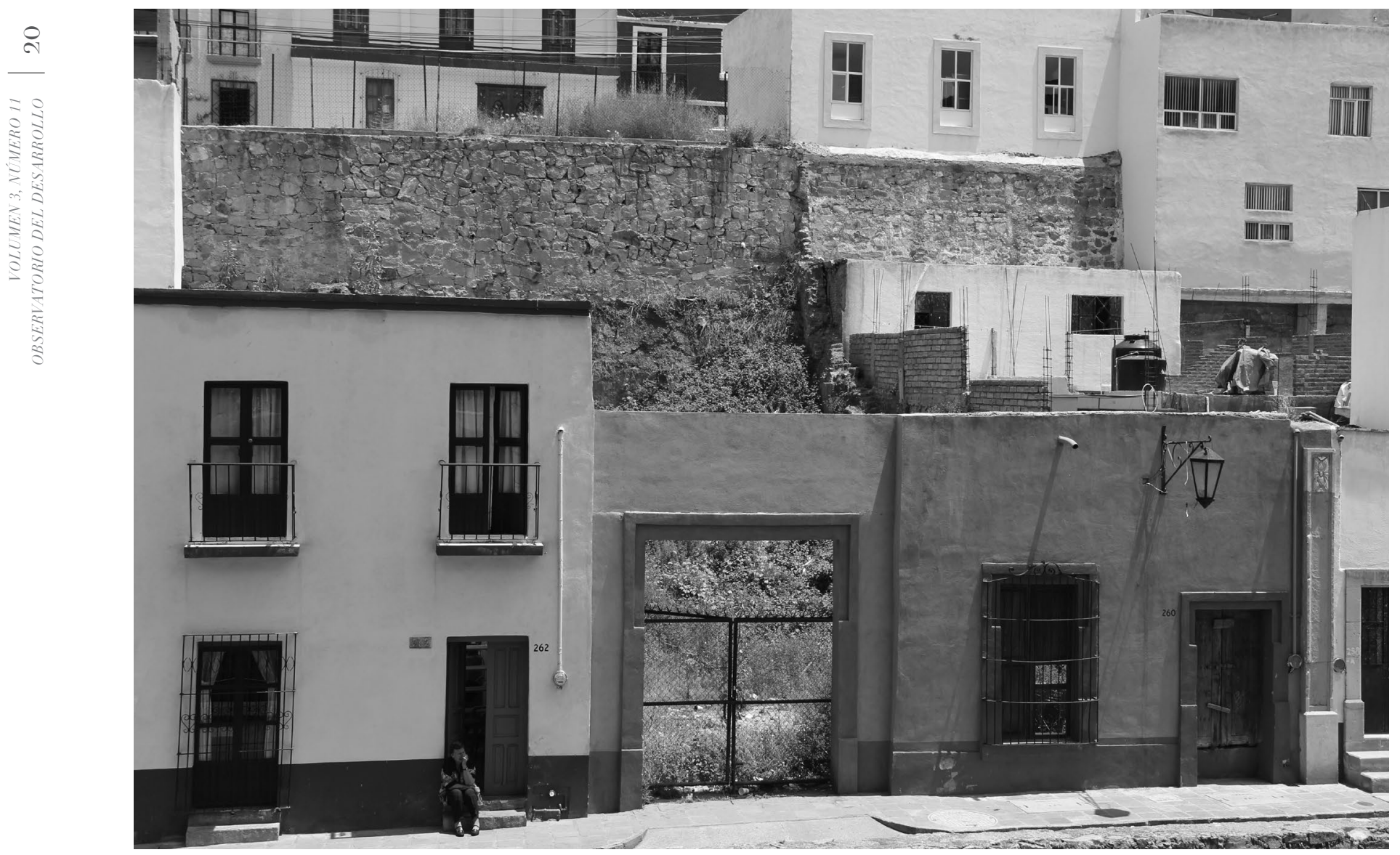

El remozamiento de fachadas del centro histórico de Zacatecas se enfrenta al problema de que una gran cantidad
de fincas está en el abandono, y en buena medida sólo disponen del frente sin estructura interna. Foto: Humberto Máreuez.

\section{Coherencia cultural fragmentada}

A principios de los años setenta fueron sentadas las bases del desarrollo del estado de Zacatecas como polo turístico. En el marco de las reformas regulatorias, la administración de Genaro Borrego Estrada (I986I992), con una activa participación de las élites regionales, amplió la infraestructura turística compuesta de cadenas hoteleras, restaurantes y diversos servicios, que incluyen al subsector cultural.

Bajo el eslogan de "Rostro de cantera y corazón de plata" se pusieron en marcha diversas estrategias que comprendieron la derrama de recursos federales y estatales en materia turístico-cultural. Para que no quedara duda alguna de que estos logros habían sido producto de la política neoliberal salinista se eligió a la ciudad de Zacatecas como sede de la Tercera Reunión Ministerial realizada los primeros días de noviembre de I99ז, previo a la firma del Tratado de Libre Comercio de América del Norte (TLCAN), en el Hotel Quinta Real y el ex Convento de San Francisco.'
A partir de ese sexenio el gobierno federal impulsó al estado de Zacatecas, cuya política cultural se orientó en cuatro rubros:

a) El rescate y restauración de la arquitectura religiosa que destaca por su riqueza cultural y monumentalidad;

b) La apertura de zonas arqueológicas, el desarrollo de museos y espacios históricos;

c) El desarrollo de industrias culturales orientado a la artesanía regional, la gastronomía y otras manifestaciones de la cultura popular, y

d) El enlazamiento con las redes de clubes de migrantes zacatecanos asentados en Estados Unidos para la subvención de fondos mixtos encaminados a impulsar programas sociales.

La proliferación de las políticas neoliberales en Zacatecas comienza con el impulso al sector turístico empresarial basado en el uso político de la cultura. En I986, Genaro Borrego decreta la creación del Instituto 
Zacatecano de Cultura (IZC) "Ramón López Velarde" y, en r99I, se funda el Centro Cultural, los cuales, posteriormente, se relocalizan institucionalmente. ${ }^{2}$

Un año después se inaugura la "Semana cultural", que a partir de 1993 se convierte en "Festival cultural", y posteriormente se extenderá a dos semanas de actividades culturales y espectáculos. Ello coincidió con la declaratoria del Centro Histórico de la capital del estado como Patrimonio Cultural de la Humanidad por la Organización de las Naciones Unidas para la Educación, la Ciencia y la Cultura (UNESCO, por sus siglas en inglés). La celebración del I Congreso Internacional de la Lengua Española en 1997, durante el gobierno de Arturo Romo Gutiérrez, generó una gran expectativa para el crecimiento de la cultura zacatecana, pero los esfuerzos organizativos se disiparon, puesto que las prioridades de la política estatal no contemplaban al subsector cultural. Quince años después se retomó este acontecimiento cultural con la celebración del Foro Iberoamericano de la Lengua Española con dos ediciones, en 2012 y 2013, como parte del Festival Internacional de la Narración Oral.

Visto de manera conjunta, estas iniciativas realizadas a finales del siglo Xx representaron las primeras señales de una política neoliberal que pretendía proyectar a Zacatecas en la cadena global del turismo, lo cual se constata con el paulatino establecimiento de franquicias internacionales de hoteles, cadenas de restaurantes, tiendas y servicios.

En los sexenios de Ricardo Monreal Ávila (19982004) y Amalia García Medina (2004-20Io), la oferta cultural se amplió con el objetivo de generar otras fuentes para la atracción de recursos económicos. Por ello se fortaleció la infraestructura museística y el circuito de festivales impulsados por el Consejo Nacional para la Cultura y las Artes (Conaculta) y el Izc: el Festival Cultural Zacatecas, el Festival Internacional de Teatro de Calle, el Festival de Narración Oral, el Festival Cultural de la Diversidad Sexual, el Festival Barroco del Museo de Guadalupe y el Festival Zacatecas del Folclor Internacional (instituido por la Secretaría de Educación y Cultura en i995).

En comparación con los sexenios priistas anteriores, los gobiernos perredistas realizaron una mayor inversión pública, la cual se denota en rubros como la habilitación de museos, la intervención y rescate de obras patrimoniales; sin embargo, no se diseñó un programa para la formación de públicos que permitiera que estas iniciativas fueran trascendentes.

En los últimos cuatro sexenios gobernados por el Partido Revolucionario Institucional (PRI), en Zacatecas se inauguró el Museo "Francisco Goitia" (1978), el Museo "Pedro Coronel" (I983), el Museo "Toma de Zacatecas"

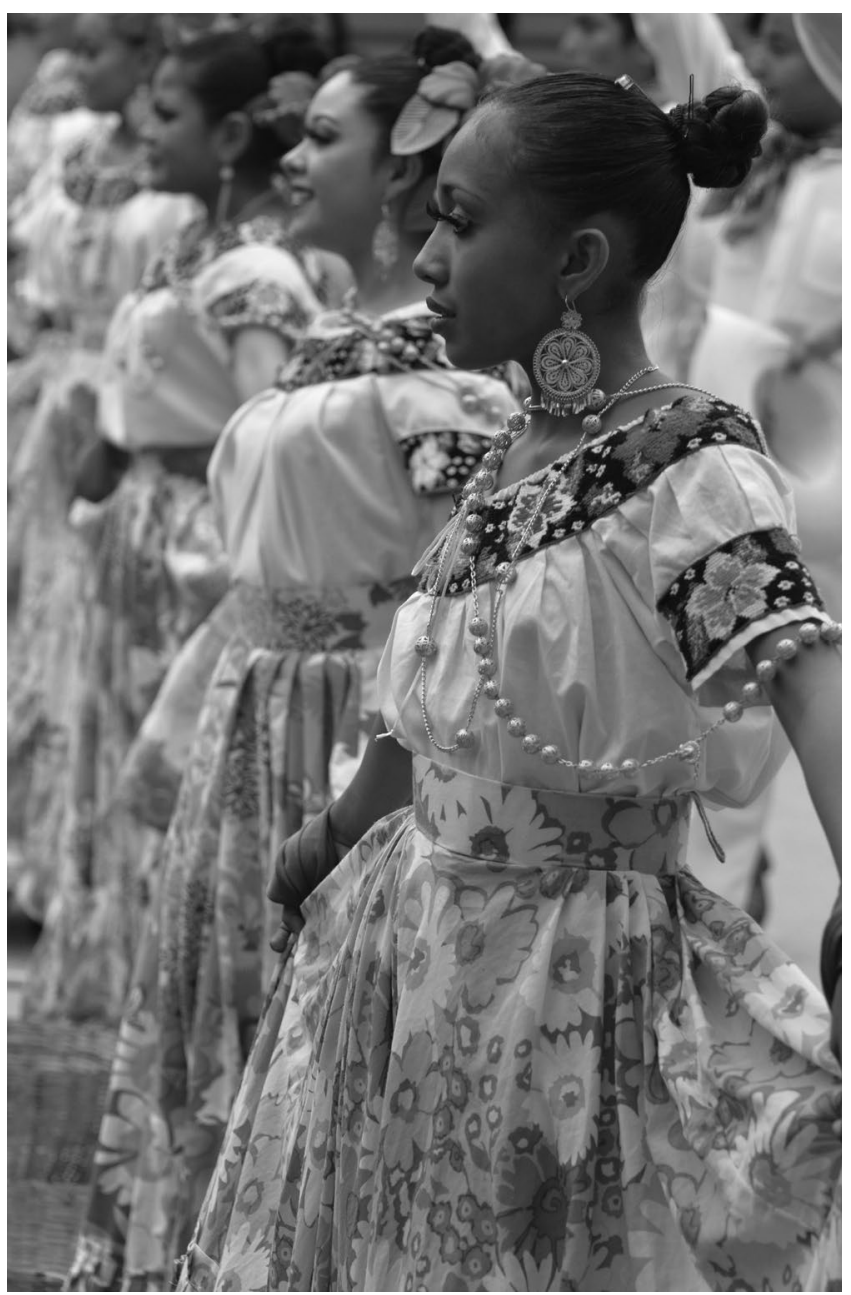

Los sucesivos gobiernos han venido eslabonando una política cultural orientada a la promoción del turismo. Los festivales tienen el cometido de diversificar la oferta de espectáculos para los visitantes.

$$
\text { Foto: Jorge VAzQUEZ. }
$$

(1984), el Museo "Rafael Coronel" (1990), el Museo Zacatecano (1995) y el Museo de Sitio "La Quemada" (I995). Mientras que en los doce años de gobierno del PRD abrieron sus puertas el Museo de Arte Abstracto "Manuel Felguérez" (1998), el Museo Comunitario de Zóquite (2003), además se remodeló el Museo de las Rocas y Minerales "Mina del Edén" (2004), se construyó el Centro Interactivo de Ciencias Zig-Zag (2005), se remodeló la Casa Museo "Ramón López Velarde" (2006), se edificó el Museo de Sitio "Alta Vista Chalchihuites" (2007) y se reubicó el Museo Zacatecano en el edificio de la Antigua Casa de Moneda (2009). En 2oro, la unesco incluyó en la lista de la Ruta de la Plata Patrimonio de la Humanidad al llamado Camino Real de Tierra Adentro que atraviesa diversos municipios del territorio zacatecano. ${ }^{3}$

Los rasgos estratégicos de la política cultural del gobierno de Ricardo Monreal fueron, primero, crear 


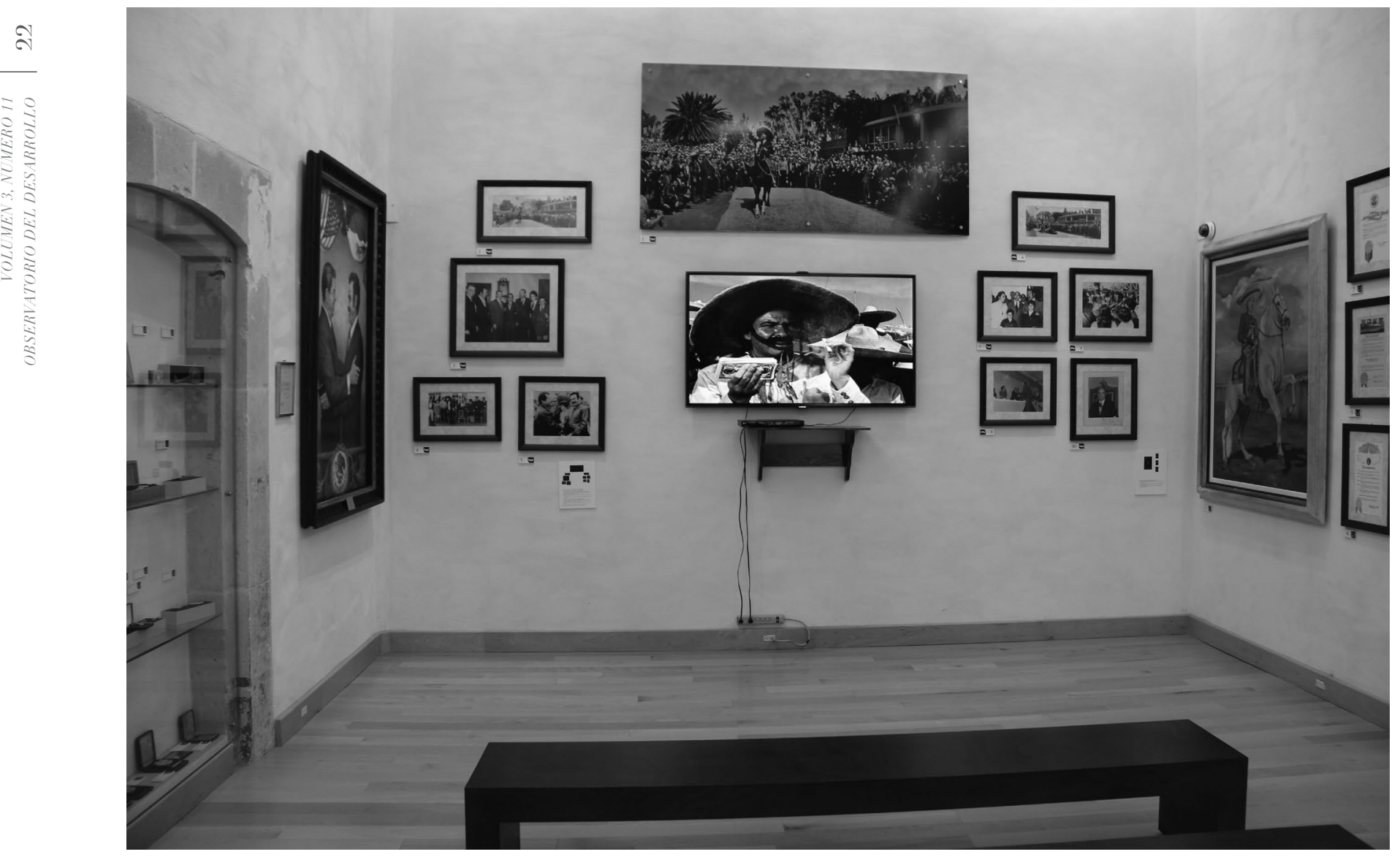

\section{Luego del deceso del cantante charro Antonio Aguilar se montó una sala de exposición con algunas de sus pertenencias en la Ciudadela del Arte.}

una base financiera para el IZC que incluía la organización por áreas y presupuesto propio, lo cual legitimó su ejercicio gubernamental. Otra línea fue el enlazamiento con los clubes de migrantes radicados en Estados Unidos que derivó en el Programa 2xi, luego denominado 3xi, para la realización de obras sociales con la mezcla de recursos federales, estatales y municipales, pero sin una estrategia educativa cultural.

Por su parte, García Medina puso énfasis en la construcción de obras magnificentes, como Ciudad Gobierno y el Centro de Convenciones, y otras de corte recreativo, como la Plaza Bicentenario y la Megavelaria en las instalaciones de la feria. Esta disparidad se reflejó en la creación del Instituto de Desarrollo Artesanal del Estado de Zacatecas (IDEAZ), que imprimió cierto aliento a la artesanía regional, así como en la recuperación e intervención de edificios patrimoniales como la Ciudadela del Arte que alberga a la cineteca y fototeca del estado.

En 2009 se inauguró el Museo de las Migraciones, ubicado en uno de los niveles del Centro de Conven- ciones, cuyo costo ascendió a alrededor de 300 millones de pesos, aunque sólo operó un año y tres meses, pues el gobierno priista entrante decidió clausurarlo y desmontarlo por considerarlo incosteable. Otros proyectos iniciados al final del sexenio anterior cuyo financiamiento fue cancelado por el gobierno de Miguel Alonso Reyes son el Hay Festival y el Centro Cultural Universitario "La Quebradilla", que incluso contó con el respaldo institucional de la Universidad Nacional Autónoma de México (UNAM). ${ }^{4}$ Este último proyecto de corte cinematográfico consistiría en el equipamiento de un laboratorio de artes visuales, un centro multimedia con sala de edición, doblaje y subtitulaje de películas, series de televisión, documentales y producciones cinematográficas, un estudio de animación y un seminario sobre temas de cine. También se proyectaba instalar una repetidora de Radio UNAM y la estación de radiodifusión XHUNZA FM con programación cultural universitaria.

En el marco del desmantelamiento del proyecto cultural perredista habría que agregar el descarte de 


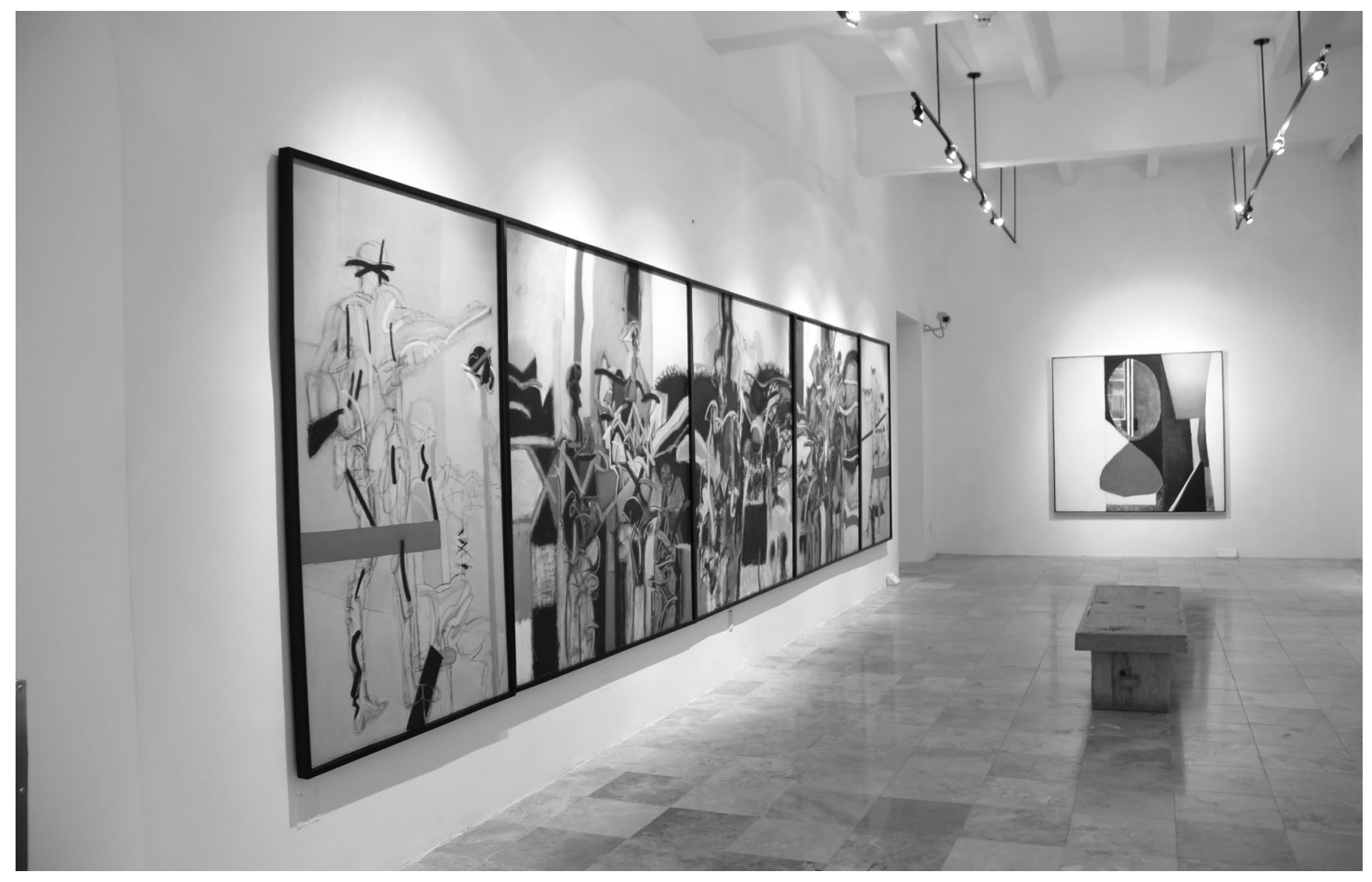

Desde el advenimiento de los gobiernos neoliberales, una fuerte inversión pública se ha canalizado para integrar un polo cultural en Zacatecas. Bajo el concepto de museos de autor se han incrementado las salas de exposición y los acervos de obra plástica.

una reforma legislativa estatal propuesta por el gobierno de García Medina para crear la Ley de Desarrollo Cultural para el Estado y Municipios de Zacatecas y la clausura de la Agenda Cultural editada mensualmente por el IZC.

Como puede observarse, las políticas públicas en materia de cultura en Zacatecas están sujetas, por un lado, a la lógica mercantil del neoliberalismo y, por el otro, al debate político sobre el patrimonio cultural según los intereses partidistas y los intereses ideológicos de los grupos que conforman la oligarquía regional. No obstante, habría que subrayar un hecho social decisivo en el devenir de la primera década del siglo xxı: el fenómeno de la violencia que irrumpió en el escenario nacional en el periodo panista (2006-2012) y cambió el esquema del proyecto cultural en Zacatecas al erosionar la oferta turística en los aciagos años de 2008-2012 y truncar la utopía mercantil neoliberal.

Esta ruptura y discontinuidad de la cultura zacatecana a lo largo de los diferentes sexenios tienen como núcleo problemático las políticas públicas desarticuladas de un proyecto transversal con los demás sectores institucionales encargados de promover la educación y la cultura. De esta forma, el IZC se encarga de operar las distintas actividades con una marcada inclinación hacia los espectáculos mediáticos, principalmente en los festivales y eventos especiales; así como administrar el programa anual de becas del Sistema Estatal de Creadores que otorga el Programa de Estímulo a la Creación y Desarrollo Artístico de Zacatecas (PECDAZ) y el Programa de Apoyo a las Culturas Municipales y Comunitarias (PACMYC), dependientes del Conaculta.

El primero se caracteriza por la sobreproducción anual de proyectos carentes de una estructura de difusión y comercialización que respalde a los beneficiarios. El segundo se encuentra dividido entre una vocación de promoción cultural y asistencial, dado que los grupos de animación subvencionados no cuentan con una estructura de mercado que permita colocar sus productos más allá de las ferias y exposiciones artesanales.

La etnia huixárica (huichol) carece de un programa de atención federal por no ser considerada un grupo originario de Zacatecas a pesar de que la ruta 


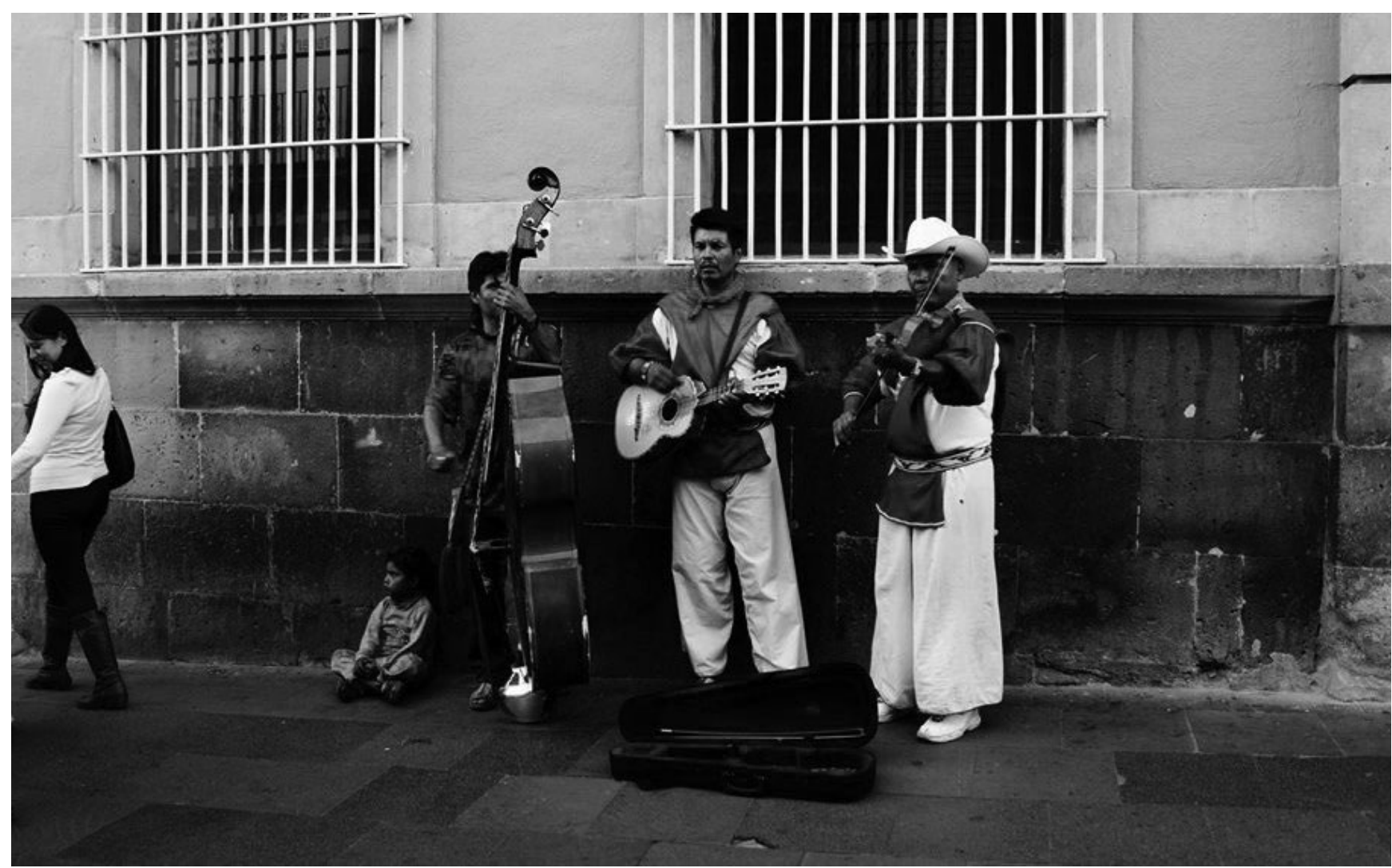

El pueblo huixárica o huichol asentado en Zacatecas se dedica a la artesanía y la música. En sus lugares de origen padecen la amenaza de despojo territorial por corporaciones extractivistas y el acoso en la ruta wirikuta

donde realizan un peregrinaje ritual.

de wirikuta incluye la veneración de sitios sagrados ancestrales y los itinerarios de peregrinaje ritual. Inclusive algunos grupos pertenecientes a esta etnia, en su mayoría artesanos, se han asentado permanentemente en los municipios de Enrique Estrada y Jerez, y aunque el gobierno del estado ha instalado albergues en estas localidades, el pueblo huichol continúa en espera de poder integrarse a un modelo de desarrollo más justo y equitativo. Pese al reclamo de esta etnia ante la constante amenaza que se cierne sobre su territorio, paisaje sagrado y autonomía indígena, este grupo indígena mantiene aún vivas las formas tradicionales de organización y evidencian las agudas desigualdades sociales que existen en el país. El caso de esta cultura indígena demuestra también el vacío de la política de Estado, que no ha resuelto sus demandas sociales y culturales por carecer de un proyecto de integración nacional.

Otro aspecto central en la problemática que atraviesa el subsistema de cultura en Zacatecas es que el sector educativo se encuentra apartado de la planeación y organización estratégica de la cultura estatal generando un vacío que imposibilita la continuidad en las políticas públicas culturales y educativas. Durante el presente sexenio, los programas culturales de la Secretaría de Educación (Seduzac) fueron desmontados del aparato educativo estatal, al grado de cambiar el nombre de Secretaría de Educación y Cultura (Seczac) por el de Seduzac, lo cual repercute directamente en la coordinación de las políticas culturales entre el IZC y los institutos municipales de cultura.

Por su parte, la Universidad Autónoma de Zacatecas (UAZ) permanece sumida en un progresivo endeudamiento financiero, una crisis de liderazgo y entrampada en las luchas políticas internas, además de condicionar la reconstrucción de su proyecto universitario. El diseño de una estrategia cultural universitaria comprometida con la recuperación de un proyecto de nación podría potencializar el desarrollo cultural del estado, siempre y cuando sus iniciativas se orienten por la función social y un programa permanente de divulgación estatal que englobe las ciencias y las artes, lo cual revitalizaría la confiabilidad hacia la UAZ en la esfera pública. 
Si bien la política cultural estatal tiene su parteaguas en el gobierno de Genaro Borrego, quien sienta las bases del proyecto neoliberal para promocionar al estado como un referente turístico cultural a nivel global, fueron las exigencias del mercado las que orientaron el curso de estas políticas por el sendero de las reformas regulatorias de la globalización. El incremento de turistas justifica los medios por lo cuales la cultura adquiere una legitimidad, aunque sea para beneficio de las élites políticas y empresariales, y para el entretenimiento del público receptor de estos discursos. La sincronía entre los regímenes neoliberales - con el Partido Acción Nacional (PAv) en la presidencia - y los gobiernos estatales del PRD, y ahora con el PRI en la Presidencia y en la gubernatura, implica que uno y otro partido han estado - inevitablemente - subordinados a las dinámicas neoliberales. De esta manera, el ciclo de las políticas públicas culturales en Zacatecas se cierra, sin que aún se consoliden socialmente.

El quehacer cultural EN PLENO LEVANTAMIENTO ARMADO

En el entorno de una severa crisis social producida por la intensa actividad del crimen organizado entre 2006 y 2012, producto de las profundas desigualdades sociales imperantes en México y la atmósfera de las elecciones federales, se produjeron distintos tipos de promesas electorales que comprendieron la reestructuración institucional de los organismos de cultura, mayor presupuesto para el sector, la creación de nuevas leyes e intensas actividades de difusión con la finalidad de combatir el flagelo social. ${ }^{5}$

La hora de confrontar las condiciones objetivas de la realidad llegó antes para el gobernador Miguel Alonso Reyes en el inicio de su sexenio, pues la política cultural estatal se vio opacada por los impactos sociales de la violencia generada durante 2006-2IO2. Ésta se caracterizó también por la restricción presupuestal de la federación y, por ende, la austera inversión en este subsector, a diferencia del sexenio anterior, donde hubo un sobregiro del gasto gubernamental en las áreas de turismo y cultura.

En su afán de desmarcarse de las políticas culturales llevadas a cabo por los dos gobiernos perredistas que lo precedieron, Alonso Reyes intentó llevar a cabo algunas iniciativas, como un programa de extensión cultural del IzC a los municipios, aunque sin una estrategia

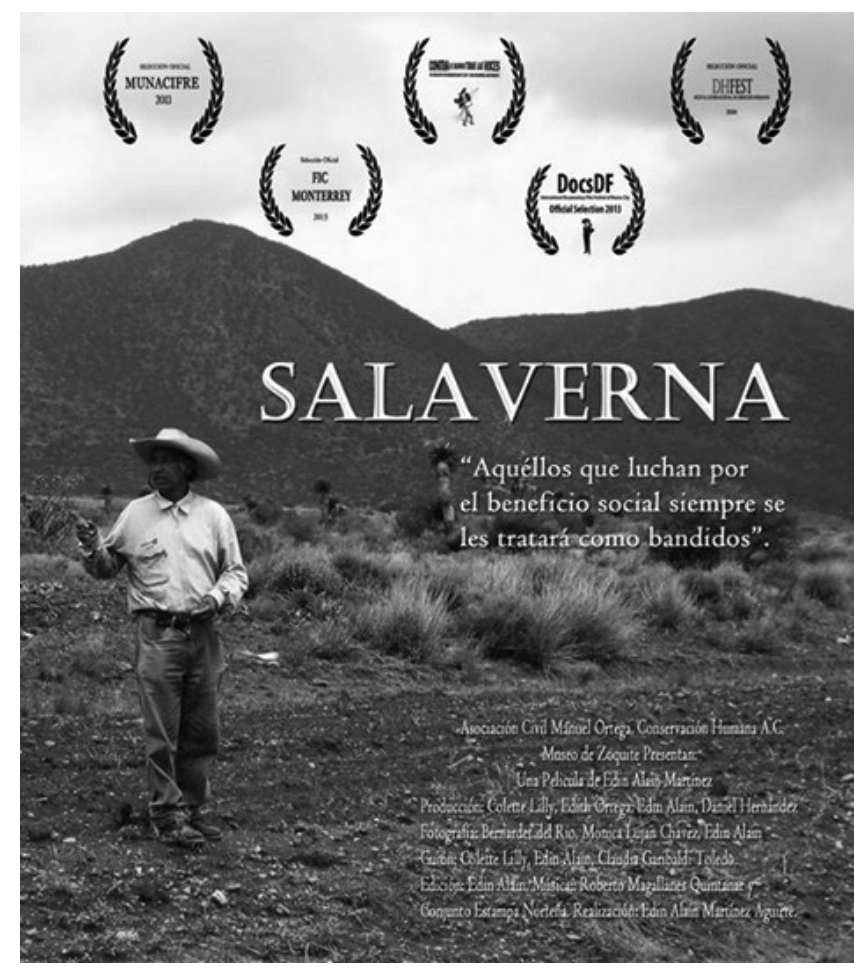

El documental Salaverna, dirigido por Edin Alain Martínez, describe el desalojo de 150 familias por la minera Tayahua de Carlos Slim, y la resistencia de unas 35 familias que deciden permanecer, aunque afrontan la presión de la empresa y el gobierno que pretenden finiquitar la expulsión.

conjunta y planificada con las instituciones educativas. Por lo cual, la restauración de los museos y la puesta en marcha del Centro Estatal de las Artes se convirtieron en los proyectos insignia del actual sexenio.

La respuesta de los artistas plásticos, creadores, investigadores y promotores culturales radicados en Zacatecas muestra una limitada participación organizativa que consolide sus iniciativas y proyectos culturales con respecto a lo que sucede en otros estados del país, como el Distrito Federal, Estado de México, Nuevo León y Jalisco, aunque ello responde a las políticas estatales de centralización. Según un reporte del Sistema de Administración Tributaria (SAT) de 2013, sólo 6.7 por ciento de las organizaciones sociales civiles donatarias autorizadas en México (6,893 asociaciones) se dedica a la actividad cultural. EI resto se distribuye en I2 rubros, entre asistenciales, deportivas, educativas, ecológicas y de servicios. Los estados con mayor número de asociaciones culturales son el Distrito Federal (2/3), Estado de México (37), Nuevo León (22), Jalisco (20), Veracruz y Oaxaca (I9), San Luis Potosí y Yucatán (I6), Chihuahua (I4), Coahuila (II). Por último, se en- 
cuentran las de menor número en el mismo rubro cultural: Michoacán (ı), Guanajuato y Sinaloa (9), Puebla (8), Baja California Norte, Querétaro y Zacatecas (6), Chiapas y Quintana Roo (5), Aguascalientes, Durango, Guerrero, Tamaulipas y Tlaxcala (4), Baja California Sur (3), Colima y Guerrero (2), Campeche (I) y Tabasco (o). ${ }^{6}$ Ello no exime que existan otras formas de organización social y de acceso a los recursos por los grupos culturales.

El desarrollo de las investigaciones en torno a la cultura zacatecana demuestra que el estado también presenta un perfil bajo en consumo cultural. ${ }^{7}$

La fragmentación de las estructuras institucionales encargadas de promover la cultura en Zacatecas y la descoordinación en este subsector se pueden considerar como un reflejo de la debilidad del proceso político interno del Estado mexicano socavado por la intromisión de los agentes trasnacionales en la socialización de las políticas públicas. La violencia e inseguridad, la división de las facciones políticas y la desorganización de masas contribuyeron, finalmente, a que los distintos proyectos culturales no lograran conseguir el resultado pretendido.

En efecto, actualmente Latinoamérica vive en un nuevo contexto de neocolonialismo económico y lumpenización social promovidos por las políticas neoliberales puestas al servicio de las exigencias mercantiles de los grandes consorcios y la reducción social del Estado. ${ }^{8}$

La reorientación de un nuevo modelo económico social más justo y equitativo que revalorice el patrimonio cultural material e inmaterial como una base del desarrollo y plantee la búsqueda de nuevos mecanismos de transversalidad entre las instituciones educativo-culturales puede contribuir a cambiar el curso de la ruta mercantilista neoliberal y lumpenizante que sigue el Estado mexicano. Para ello es necesario el compromiso de los agentes involucrados y una ciudadanía activa y reflexiva que se guíe por un proyecto de integración nacional, abierto hacia el exterior y con un horizonte humanista, lo cual constituye el único garante para encaminar nuevamente al país hacia el florecimiento de la cultura y la búsqueda de un bienestar común.

\section{- notas $\cdot-$}

'Sergio Candelas (2014), "Zacatecas, pilar en el TLCAN", El Sol de Zacatecas, 27 de enero, pp. I-9 A.

${ }^{2} \mathrm{http}$ //www.congresozac.gob.mx/e/todojuridico\&cual=23.

3"México Desconocido" (2012), Guía Especial Museos de Zacatecas, núm. 5o, pp. 8-86.

4Raúl García (20ıo), "Crearán Centro Cultural Universitario, La Quebradilla", El Sol de Zacatecas, 6 de agosto de 20Iо, pp. I-6 A.

5udith Amador Tello (2012), "Política cultural... lo que sigue", Proceso, núm. г86.
${ }^{6} \mathrm{http}: /$ www.sat.gob.mx/terceros_autorizados/donatarias_ donaciones/Paginas/directorio_donatarias.

־Consejo Nacional para la Cultura y las Artes (2010), Encuesta Nacional de Hábitos y Consumo Culturales 2010. Prime- ros resultado por entidad federativa, México, Conaculta, pp. 344-354; Manuel Delgado (20II), "Investigación de mercados de tipo exploratoria", Universidad Tecnológica de Zacatecas, documento electrónico.

${ }^{8}$ Gonzalo Castellanos (2010), Patrimonio cultural. Integración y desarrollo en América Latina, México, Fondo de Cultura Económica, p. I8. 